\title{
Effects of Inflammatory Conditions on Liver Activity in Puerperium Period and Consequences for Performance in Dairy Cows
}

\author{
G. Bertoni, ${ }^{1}$ E. Trevisi, X. Han, ${ }^{2}$ and M. Bionaz ${ }^{3}$ \\ Istituto di Zootecnica, Facoltà di Agraria, UCSC, via Emilia Parmense 84, 29100 Piacenza, Italy
}

\begin{abstract}
The relationship between inflammation and general health conditions in dairy cows and the link between inflammation, liver function, and fertility are poorly understood. To clarify these relationships, 120 multiparous dairy cows were followed throughout an entire lactation. Blood samples were collected during the first month of lactation for a metabolic profile, and milk yield, disease occurrence, and fertility parameters were monitored during the entire lactation. Twentyfour cows were culled, and another 19 were excluded because they had serious problems after $30 \mathrm{~d}$ in milk (DIM) and before the first insemination. The remaining 77 cows were pregnant at the end of lactation and were retrospectively grouped into quartiles based on liver activity index (LAI), which is based on plasma negative acute phase proteins. Cows in the lower (LO) and intermediate lower (INLO) quartiles of LAI had more severe inflammations with high concentrations of haptoglobin $(0.77$ and $0.61 \mathrm{~g} / \mathrm{L})$ and globulin $(42.5$ and $39.0 \mathrm{~g} / \mathrm{L})$, respectively, during the first week of lactation compared with cows in the upper (UP) and intermediate upper (INUP) quartiles of LAI (haptoglobin: 0.28 and 0.45 $\mathrm{g} / \mathrm{L}$, and globulin: 34.2 and $36.9 \mathrm{~g} / \mathrm{L}$, respectively). At 7 DIM, the cows in LO and INLO had greater bilirubinemia (8.7 and 10.5 vs. $6.3 \mu \mathrm{M} / \mathrm{L}$ in UP) and lower blood urea (3.5 and 3.7 vs. $4.1 \mathrm{~m} M$ in UP). The INLO group exhibited more days open (139 vs. 93) and services per pregnancy (2.68 vs. 1.65), but lower milk yield (38.3 vs. $40.8 \mathrm{~kg} / \mathrm{d}$ at $28 \mathrm{DIM}$ ) compared with UP. The LO group did not have a significantly lower fertility status, but presented the lowest milk yield $(34.1 \mathrm{~kg} / \mathrm{d}$ at 28 DIM). Our data suggest that cows with lower LAI scores had a more pronounced inflammatory status during the first month of lactation, an impairment of
\end{abstract}

Received January 4, 2008.

Accepted May 15, 2008.

${ }^{1}$ Corresponding author: giuseppe.bertoni@unicatt.it

${ }^{2}$ Present address: Herd Nutrition Specialist, Nobleford, Alberta, TOL 1S0 Canada.

${ }^{3}$ Present address: Department of Animal Sciences, University of Illinois, 428 ASL, Urbana, 61801. usual hepatic functions (e.g., bilirubin clearance), and a larger negative energy balance. The same cows had poorer performance (lower milk yield and fertility) than cows with higher LAI scores. Overall data suggest that any effort to avoid the acute phase response in the transition period would be useful for optimizing the productive and reproductive performance of highyielding dairy cows.

Key words: acute phase response, blood index, fertility, liver activity index

\section{INTRODUCTION}

The puerperium period of dairy cows is often characterized by inflammatory conditions (Cappa et al., 1989). These conditions are likely the result of proinflammatory cytokine release (Grimble, 1990). Several causes of proinflammatory cytokine release in dairy cows around parturition such as infectious or metabolic diseases, parasites, trauma, endotoxins from the gut, or stresses (Grimble, 1990) have recently been highlighted in a review by Drackley et al. (2005).

The potential effects of proinflammatory cytokines in periparturient cows can change according to the amount and the time of their release; however, main effects concern liver synthesis, nutrient partitioning, anorexia, and reproductive activity. The major effect of cytokines in liver is the stimulation of acute phase response (Fleck, 1989), which is characterized by induction of positive acute phase protein (+APP) synthesis, mostly detected in blood plasma (e.g., haptoglobin and ceruloplasmin) and the impairment of hepatic synthesis of negative acute phase proteins (-APP), such as albumin and retinol binding protein (Fleck, 1989) as well as apolipoproteins (Bruss, 1997). The cytokines induce immune stress and associated metabolic diversions from the normal patterns of nutrient channeling (i.e., assimilation for growth and development) to increase heat production (fever), and synthesis of unusual proteins in liver and immune system tissues (Elsasser et al., 2000). The effect of cytokines in worsening the anorexic status can occur at parturition as demonstrated in general by Johnson and Finck (2001) and by our partly published data (Trevisi et al., 2002). A negative 
interference of cytokines can occur with reproductive activity due to inopportune release of LH (Braden et al., 1998) or progesterone from adrenal glands (Trevisi et al., 1996a), and to a large release of $\mathrm{PGF}_{2 \alpha}$ (Fredriksson et al., 1985).

All these effects could contribute to the impairment of milk yield (Bionaz et al., 2007) and fertility (Calamari et al., 1997; Bertoni et al., 2000), as observed in cows with blood abnormalities of inflammatory indices in the first weeks of lactation. Interestingly, lower fertility has been detected in cows with peripartum metabolic diseases (Markusfeld et al., 1997; Beaudeau et al., 2000) and with infectious diseases such as mastitis (Schrick et al., 2001). In addition, Barton et al. (1996) reported that excess crude protein (high blood urea) reduces the reproductive efficiency only in cows with major health problems. Furthermore, Roche et al. (2000) concluded that "high reproductive efficiency in the dairy cow requires a disease-free transition period"; and similar findings were reported by Lucy (2001). Finally, the effects of cytokines on tissue priority for nutrients (Elsasser et al., 2000), on DMI (Johnson and Finck, 2001), and on liver synthesis diversion (Fleck, 1989) can exacerbate the negative energy balance (Pryce et al., 2001) and increase the risk of liver lipidosis (Bertoni et al., 2000; Katoh, 2002), both of which are causes of reduced reproductive efficiency (Butler, 2000).

The aim of our study was to evaluate the relationship between inflammation, evaluated by blood indices around parturition, particularly those affected by liver activity (+APP and -APP), and health conditions as well as cow performance (milk yield and reproduction efficiency).

\section{MATERIALS AND METHODS}

\section{Animals and Feeding System}

One hundred twenty multiparous Holstein-Friesian dairy cows were followed throughout lactation. They calved in the autumn-winter season from 1999 to 2001 and they belonged to 3 different herds in the Po Valley (Italy) and had good genetic merit (on average, over 9 t/lactation; Table 1). Cows were kept in loose-housing stalls and divided into 4 groups: dry, close-up, freshaverage, and late lactation. Dry cows were moved into the parturition pen about 7 to $10 \mathrm{~d}$ before expected parturition. Dry and lactating cows of the 3 herds were fed with a TMR once daily, except for the dry cows of herd 2 , which received hay ad libitum. Samples of each feed were taken every 2 mo for chemical (moisture, fat, CP, crude fiber, NDF, starch, ash) and nutritional evalu- ation according to Martillotti et al. (1987) and NRC (2001), respectively. Energy and protein requirements were estimated according to NRC (2001). In addition, the feed intake of each herd (separately for dry and lactating cows) was estimated weekly during the trial; the group amounts of TMR and refusals after $24 \mathrm{~h}$ were recorded (DMI was calculated according to these data and to the feed analysis).

\section{Blood Analysis}

Blood was collected weekly beginning 1 to 2 wk before the expected date of parturition, within $24 \mathrm{~h}$ after parturition, and at 7, 14, and $28 \mathrm{~d}( \pm 2 \mathrm{~d})$ of lactation. Blood was collected in the morning (before TMR distribution) from the jugular vein into evacuated tubes containing Li-heparin as an anticoagulant (Vacutainer, Becton Dickinson, Plymouth, UK).

A small amount of blood was used for hematocrit (packed cell volume) determination (Centrifugette 4203, ALC International Srl, Cologno Monzese, Italy), and the remainder was centrifuged within $1 \mathrm{~h}$ of collection at 3,500 $\times \mathrm{g}$ for $15 \mathrm{~min}$; the plasma was frozen $\left(-20^{\circ} \mathrm{C}\right)$ in several fractions until further analysis. Blood metabolites were analyzed at $37^{\circ} \mathrm{C}$ by using a clinical auto-analyzer (ILAB 600, Instrumentation Laboratory, Lexington, MA). Total protein, albumin, total cholesterol, total bilirubin, triglycerides, creatinine, urea, $\mathrm{Ca}, \mathrm{P}, \mathrm{Mg}$, aspartate aminotransferase (AST/GOT), Y-glutamyl transpeptidase (GGT), alkaline phosphatase, and lactate dehydrogenase were determined using kits purchased from Instrumentation Laboratory (IL Test). Globulin was calculated by the difference between total protein and albumin. Ions $(\mathrm{Na}$, $\mathrm{K}$, and $\mathrm{Cl}$ ) were detected by the potentiometer method (ion-selective electrode connected to ILAB 600). Zinc, NEFA, haptoglobin, BHBA, and ceruloplasmin were determined using the methods previously mentioned (Bionaz et al., 2007). Plasma retinol was analyzed by the fluorimetric method described by Kahan (1971).

\section{Milk Yield, BCS, and Health Problems}

Individual milk yield was monitored weekly during the first month of lactation and then monthly until the end of lactation. The BCS was evaluated before parturition and then weekly during the first 2 mo of lactation according to a 5-point scale (Agricultural Development and Advisory Service, Alnwick, UK). In addition, occurrences of all health problems, drug treatments, outcomes of the 30 DIM gynecological visit, insemination services, and culling causes were accurately recorded for each cow throughout the entire lactation. 
Table 1. Herd characteristics, ingredients, and main chemical and nutritional traits (\% of DM) of the diets utilized during the period of interest as TMR for close-up and lactating cows of the 3 herds (cows in the first month of lactation were included in the fresh-average lactating group)

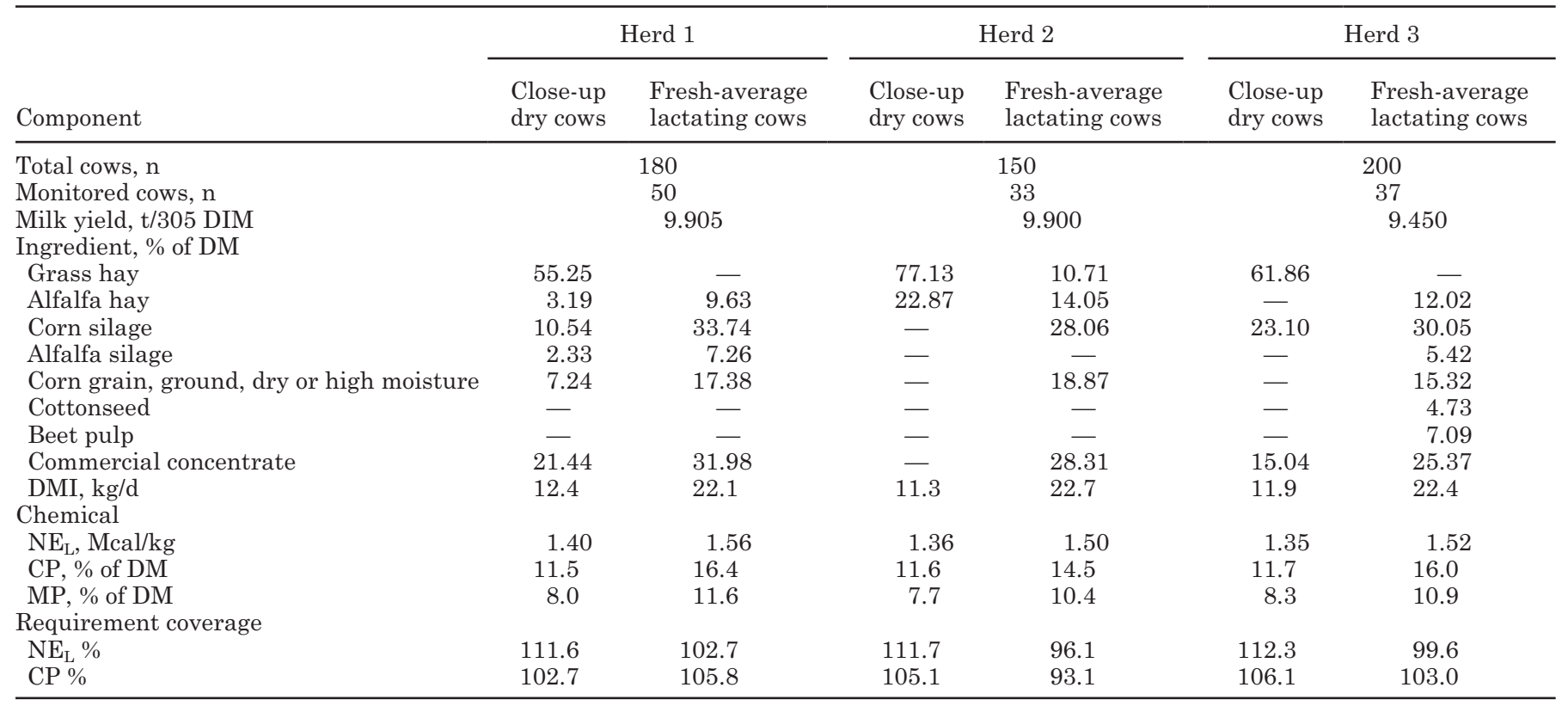

\section{Data Handling and Groups}

Data were retrospectively evaluated considering only 77 of the initial 120 cows. Twenty-four cows were culled: 14 cows had serious health problems (ketosis, mastitis, abomasum displacement) that occurred within the first 30 DIM rendering impossible a proper blood check; the remaining 10 culled cows were infertile. This last small group had an unbalanced distribution among the farms; thus, it was a difficult group to be managed. Another 19 cows were excluded from the data set, even though they were pregnant, because of serious health problems in the reproductive period (from 30 DIM to the first insemination) that could have interfered with fertility. Some (63\%) were characterized by clinical symptoms (e.g., lameness, metritis, fever), whereas the remaining $37 \%$ were identified for a large reduction of milk yield (20\% or more) and a contemporary increase of plasma haptoglobin concentration $(>0.3 \mathrm{~g} / \mathrm{L})$.

The remaining 77 pregnant cows were retrospectively grouped into quartiles based on the liver activity index (LAI; Trevisi et al., 2001). This aggregate index includes the average blood level (7, 14, and 28 DIM) of some proteins synthesized by the liver: albumin, lipoproteins (indirectly measured as total cholesterol; Bruss, 1997), and retinol-binding protein (RBP) because the retinol released from the liver depends mainly on the synthesis of apo-RBP (Wolf, 1984). Data of these 3 blood parameters were transformed into units of standard deviation obtained for each cow as follows: the mean value of the herd population of each plasma parameter (albumin, total cholesterol, and RBP) was subtracted from each cow value at 7, 14, and 28 DIM and divided by the corresponding standard deviation. Thus, the final LAI of each cow is the result of the arithmetical mean of the 3 partial values obtained from the 3 selected blood indices at the 3 bleedings.

In the present study, LAI was calculated within each herd to include the herd effect. Subsequently, cows of each herd were grouped into quartiles according to the LAI: upper quartile (cows with the highest values of LAI in each of the 3 herds; UP, $n=19$ ); intermediate upper quartile (group INUP, $\mathrm{n}=19$ ); intermediate lower quartile (group INLO, $\mathrm{n}=20$ ); and lower quartile (cows with the lowest values of LAI, group LO, $\mathrm{n}=19$ ).

To better justify the exclusion of the problem group of 19 pregnant cows, it must be considered that they had few health problems in the first 30 DIM, similar to the intermediate groups INUP and INLO; also similar in that period was the pattern of blood profile behavior. On the contrary, the major differences concerned the occurrence of serious health problems in mo 2 to 3 of lactation. According to Barton et al. (1996) and Schrick et al. (2001), health problems can impair cow fertility, which is confirmed by our data. For these reasons, we preferred to exclude the problem animals from the statistical evaluation aimed to evaluate the effects of inflammation occurring around parturition. 


\section{Statistical Evaluation}

Data measured over time (milk yield, BCS, and plasma components) within the period of interest were aggregated according to DIM: 7, 14, and 28 (values correspond to the real time $\pm 2 \mathrm{~d}$ ). These data were subjected to ANOVA using the REPEATED statement in the MIXED procedure of SAS (SAS Inst. Inc., Cary, NC; release 8.0). The statistical model included the fixed effect of group (UP, INUP, INLO, LO), DIM (7, $14,28)$, and group by DIM interaction. The random variables were herd and cow within group ( $\mathrm{n}=19$ for UP, $n=19$ for INUP, $n=20$ for INLO, $n=19$ for LO). Each parameter was tested for normal distribution using the Shapiro test (SAS Inst. Inc.) and normalized by logarithmic transformation when necessary. The covariance structure used was the autoregressive order, because it fit the model better. Prevalence of health problems recorded during the study were subjected to $\mathrm{X}^{2}$ analysis (PROC FREQ of SAS) to determine whether prevalence differed among groups. Fertility indices were normalized using logarithmic transformation, and then analyzed by one-way ANOVA (SAS Inst. Inc.). The lactation curves of each cow were estimated according to the Wood equation (Proc NLIN of SAS analyzed by one-way ANOVA), and curve indices were analyzed by one-way ANOVA. In addition, Pearson correlations between blood parameters were calculated within each quartile. Statistical significance was designated as $P$ $<0.05$.

\section{RESULTS}

\section{General Situation of the Herds}

As shown in Table 1 , the 3 herds were of high genetic merit (more than 9 t/lactation). The diets were different between herds and production groups (dry and fresh-average lactating cows), but they showed satisfactory composition (Table 1) according to NRC requirements (NRC, 2001). Lactating cows of herds 1 and 3 received similar diets, whereas the diet for herd 2 had the greatest DMI but lower energy and protein concentration. Thus, the average satisfaction of energy and protein requirements of all groups was not less than $90 \%$ (Table 1). Body condition score revealed that body reserve levels and utilization were similar in the 3 herds. A satisfactory BCS was observed before parturition $(3.02 \pm 0.29,2.67 \pm 0.24$, and $3.00 \pm 0.15$ points in the 3 farms, respectively); then, a progressive reduction occurred, with the lowest score at wk 6 of lactation (approximately 0.7 points lower).

\section{Blood Analysis}

The individual values of LAI ranged from +1.22 to -1.51 , and the average levels for the quartile groups were $0.71 \pm 0.31,0.18 \pm 0.17,-0.20 \pm 0.19$, and -0.67 \pm 0.29 for UP, INUP, INLO, and LO groups, respectively.

Blood albumin, RBP, and total cholesterol (Figure 1) used for LAI indices of usual liver activity had the typical postpartum pattern of change overall; namely, low values in the first days of lactation with a gradual increase thereafter. Nevertheless, the UP group, according to the grouping criteria, was characterized by the greatest values and by the quickest increase of LAI parameters during the first month of lactation. Significantly lower values during the whole month were observed for the LO group, which, however, had a good recovery of the 3 parameters (Figure 1).

The +APP ceruloplasmin and haptoglobin (Table 2 and Figure 2, respectively) had the greatest values at 7 DIM and a gradual reduction thereafter. The UP group had the lowest value for haptoglobin, and the LO group had the greatest (Figure 2). Ceruloplasmin did not differ significantly between groups immediately after parturition; however, its level decreased faster in the UP group than in the LO group.

Other differences between groups were summarized in Table 2, but appear to be less important. Briefly, packed cell volume tended to decline after parturition and during the first month of lactation; it was lower in the LO group than in the UP group ( 0.29 vs. 0.31 $\mathrm{g} / \mathrm{L} ; P<0.05$ ). Calcium and $\mathrm{Mg}$ were lower during the first week of lactation and increased thereafter (faster in the UP group). However, during the first month of lactation, the LO group had a lower value of $\mathrm{Ca}$ than did the UP group; $\mathrm{Mg}$ concentration was lower in the LO group than in the UP group during the first 2 wk of lactation, but thereafter the differences disappeared. The LO and INLO groups had lower plasma urea concentrations than the INUP and UP groups. Comparing the 4 groups, it appears that LO and INLO had significantly greater values of bilirubin compared with UP, particularly during the first 7 DIM (Figure 2), and significantly greater values of globulin for the whole first month of lactation (Table 2). Levels of NEFA and BHBA were greater during the first week of lactation in LO and INLO groups-despite rarely being above the risk levels $(>1.0$ and $>1.2 \mathrm{~m} M$, respectively for NEFA and BHBA; Table 2). Thereafter, both parameters had a general reduction, albeit faster for LO and slower for INLO. On the contrary, glucose and enzymes (Table 2) including GOT and GGT did not exhibit any significant difference between groups. 


\section{Health Problems}

Major disease frequency for each group is reported in Table 3. The UP group had better overall health immediately after parturition and during the first month of lactation. The INLO group exhibited the worst health situation in the transition period (if metritis is excluded) because retained placenta was frequent
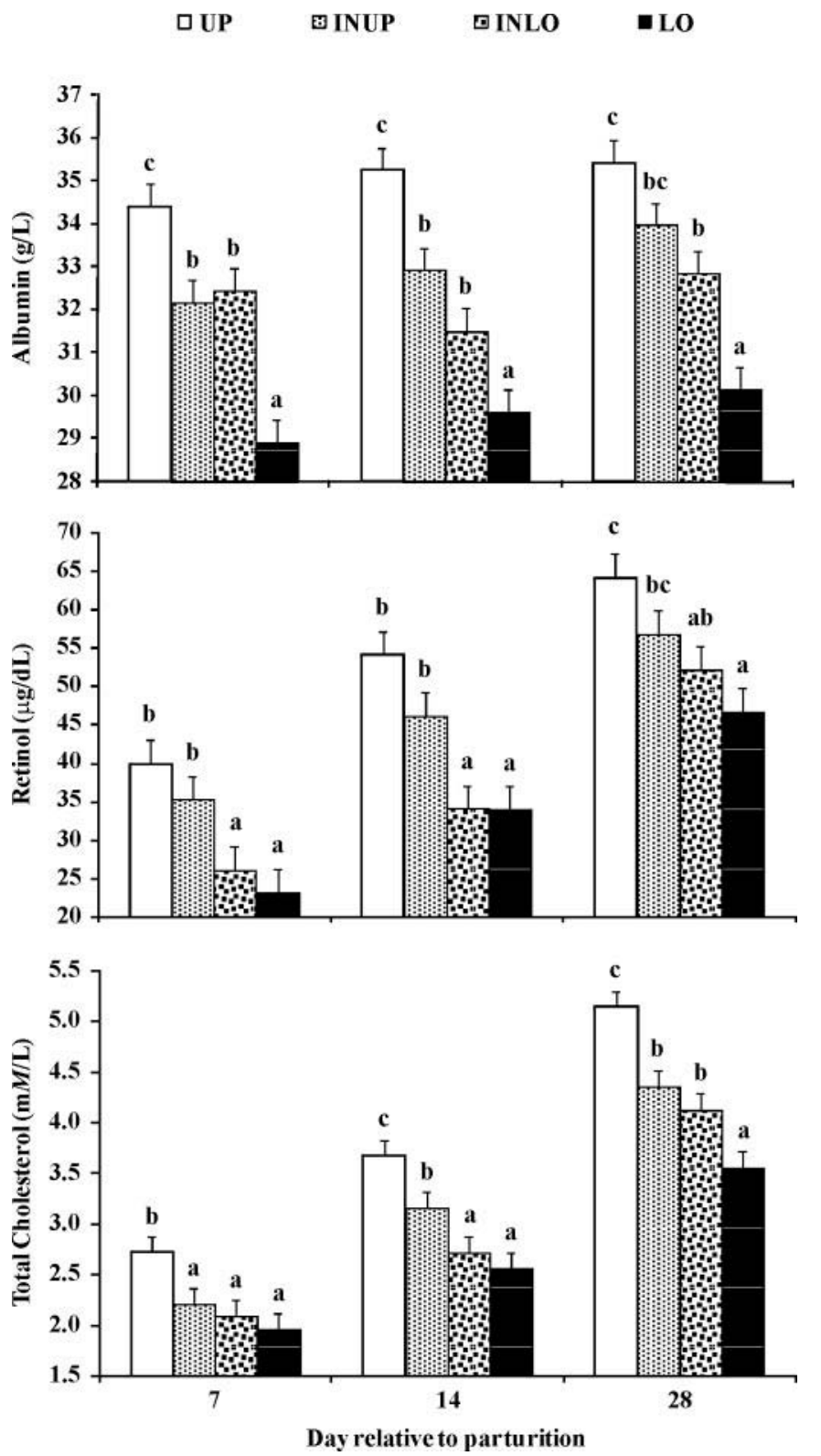

Figure 1. Plasma indices of negative acute phase proteins (albumin, retinol, and total cholesterol) observed in the first month of lactation in the cows within upper (UP), intermediate upper (INUP), intermediate lower (INLO), and lower (LO) quartiles of liver activity index (LAI). ${ }^{a-c}$ For each blood parameter, a significant $(P<0.05)$ difference between groups at the same DIM is shown by different letters. in this group (21\%), but also because during the first month of lactation, the cows had a high incidence of lameness (21\%). The LO group presented a better situation than the INLO group, but metritis incidence was particularly high ( $26 \%$ vs. $5 \%$ in the other groups). In these 2 groups, almost $50 \%$ of cows (17 of 38 ) suffered clinical problems in the first month of lactation; the remaining cows, despite inflammatory responses, did not have any clinical symptoms.

\section{Reproductive Parameters}

The UP group presented the best fertility indices (Table 3): 1.6 services per pregnancy, 93 days open, a first-service conception rate of $53 \%$, and the lowest frequency of repeat breeders (21\%). The LO group had impaired fertility compared with UP but with 2 services per pregnancy, $110 \mathrm{~d}$ open, a first-service conception rate of $37 \%$, and $32 \%$ repeat breeders, the LO group was better than the INUP and INLO groups. However, the INLO group had the worst indices among the quartile groups: 2.7 services per pregnancy, $139 \mathrm{~d}$ open, and $21 \%$ first-service conception rate.

As already mentioned, the 19 pregnant cows excluded as problem animals had the worst reproductive indices: $2.60 \pm 1.3(P<0.05$ vs. UP) services per pregnancy, $157.6 \pm 55(P<0.05$ vs. UP) days open, and $16 \%$ (vs. $53 \%$ of UP) first-service conception rate.

\section{Milk Yield and BCS}

Milk yield during the first month of lactation (Table 2 ) was greater in UP, lower in LO ( $P<0.05$ vs. UP), and intermediate in the other groups. The overall milk production during the first 3 mo of lactation was greater in the UP group, but no significant differences were observed (mean \pm SD: $3.45 \pm 0.7,3.30 \pm 0.8,3.31$ \pm 0.7 and $3.03 \pm 0.8 \mathrm{t} / \mathrm{cow}$ for UP, INUP, INLO, and $\mathrm{LO}$, respectively). With regard to the nutrition status (Table 2), the INLO group had greater BCS loss during the first 42 DIM after calving compared with the other groups; in fact, the BCS reduction was $0.79 \pm 0.38,0.70$ $\pm 027,0.69 \pm 0.36$, and $0.67 \pm 0.30$ points for INLO, INUP, LO, and UP respectively.

\section{DISCUSSION}

The objective of this study was the evaluation of blood parameter changes during the peripartum period in dairy cows, especially for markers of liver response to inflammatory phenomena; moreover, the relationship between impaired liver functions and reproductive response and milk yield was assessed. All of these aspects will be discussed separately and possible interactions 
Table 2. Trend of BCS, milk yield, plasma metabolites, and other blood parameters during the first month of lactation in groups of upper (UP), upper intermediate (INUP), lower intermediate (INLO), and lower (LO) quartiles of liver activity index (LAI)

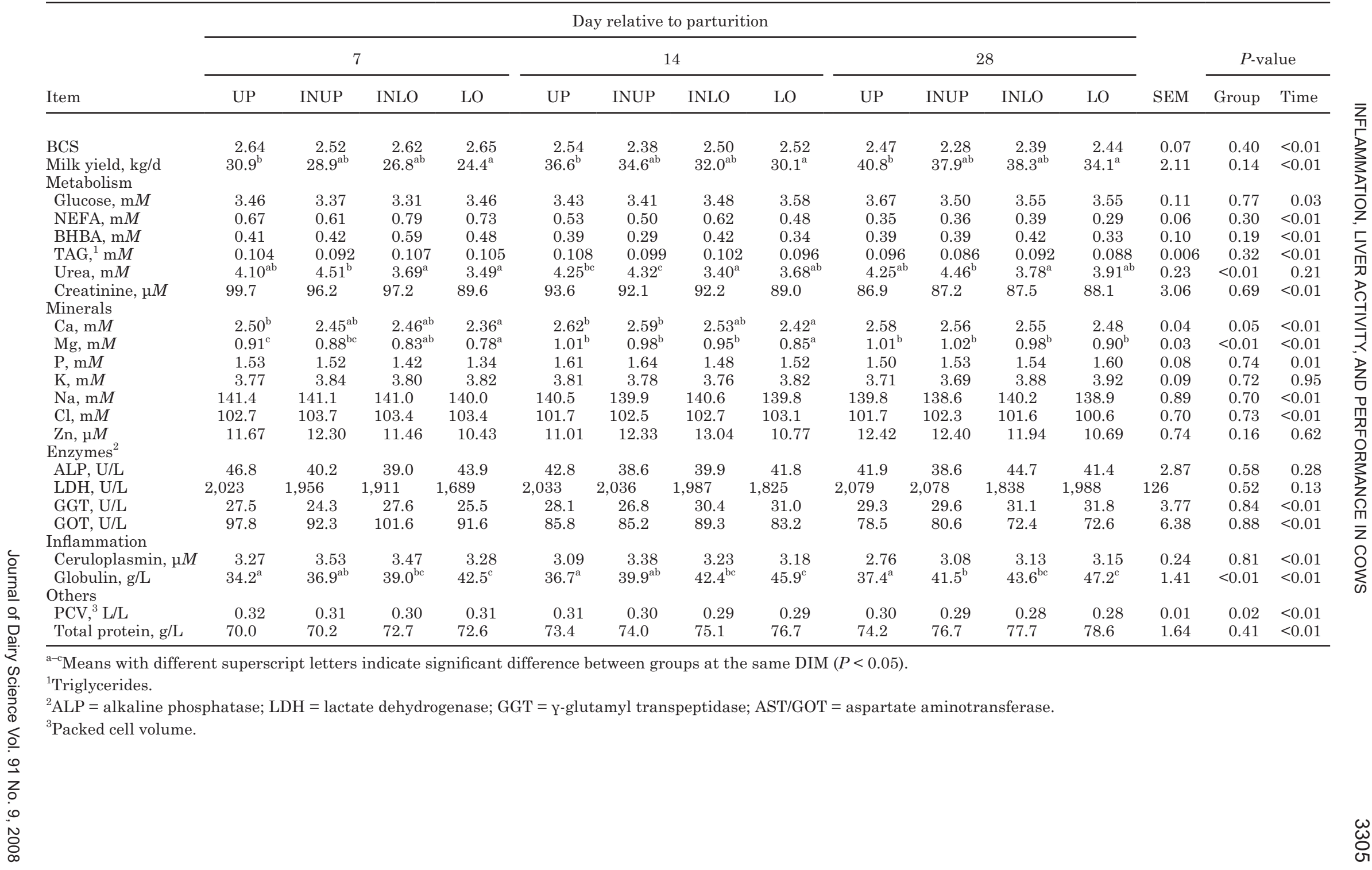



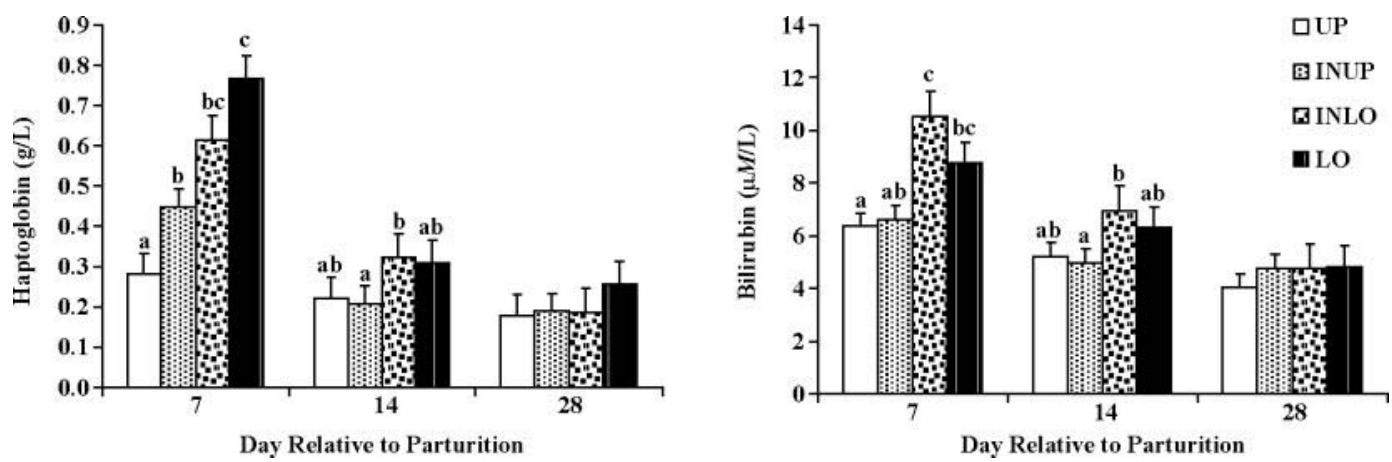

Figure 2. Pattern of haptoglobin (positive acute phase protein) and bilirubin (index of hepatic bilirubin clearance) observed during the first month of lactation in cows within upper (UP), intermediate upper (INUP), intermediate lower (INLO), and lower (LO) quartiles of liver activity index (LAI). ${ }^{\mathrm{a}-\mathrm{c}}$ For each blood parameter, a significant $(P<0.05)$ difference between groups at the same DIM is shown by different letters.

will be taken into account. It is important to highlight that the grouping criteria allowed the distribution of the same number of cows from each herd into the $4 \mathrm{LAI}$ groups, so the differences in herds are not of concern.

\section{Inflammatory Conditions and Liver Functions}

The values after 7 DIM of haptoglobin (Figure 2), an index of acute phase response that we consider acceptable when below $0.2 \mathrm{~g} / \mathrm{L}$, clearly highlighted that a large portion of periparturient cows were affected by inflammatory phenomena; these data confirm previous results from our laboratory (Cappa et al., 1989; Calamari et al., 1997). Nevertheless, almost all the cows of the UP group and some of the INUP group had lower values of haptoglobin, suggesting that some cows were not affected by inflammatory phenomena as confirmed by the low values of globulin, especially at $7 \mathrm{DIM}$ (Table 2). In fact, the more or less serious inflammatory conditions suggested by haptoglobin levels have been confirmed by the plasma globulin increase in groups INUP, INLO, and LO. This acute phase response of the liver was accompanied by a decrease in plasma of the negative acute phase proteins, which are abundantly synthesized in the liver under normal condition (Powanda, 1980; Fleck, 1989). In fact, haptoglobin was inversely correlated with retinol $(\mathrm{r}=-0.47, P<0.001)$ and cholesterol $(\mathrm{r}=-0.42, P<0.001)$ as well as with albumin $(\mathrm{r}=-0.22, P<0.001)$. Much weaker, but still statistically significant, was the correlation of haptoglobin with ceruloplasmin $(r=0.23, P<0.001)$, another positive acute phase protein.

Table 3. Frequency of health problems and fertility indices in upper (UP), upper intermediate (INUP), lower intermediate (INLO), and lower (LO) quartiles of liver activity index (LAI)

\begin{tabular}{|c|c|c|c|c|c|}
\hline \multirow[b]{2}{*}{ Item } & \multicolumn{4}{|c|}{ Group } & \multirow[b]{2}{*}{$P$-value } \\
\hline & UP & INUP & INLO & $\mathrm{LO}$ & \\
\hline \multicolumn{6}{|l|}{ Health problems ${ }^{1}$} \\
\hline At parturition & $0.0^{\mathrm{a}}$ & $5.0^{\mathrm{a}}$ & $36.9^{\mathrm{b}}$ & $21.1^{\mathrm{b}}$ & $<0.01$ \\
\hline After parturition & $5.3^{\mathrm{a}}$ & $30.0^{\mathrm{b}}$ & $42.2^{\mathrm{b}}$ & $31.7^{\mathrm{b}}$ & 0.21 \\
\hline Metritis & $0.0^{\mathrm{a}}$ & $5.0^{\mathrm{a}}$ & $5.3^{\mathrm{a}}$ & $26.3^{\mathrm{b}}$ & 0.02 \\
\hline Cows with problems ( 1 or more) & $5.3^{\mathrm{a}}$ & $26.3^{\mathrm{b}}$ & $45.0^{\mathrm{b}}$ & $42.1^{\mathrm{b}}$ & $<0.01$ \\
\hline \multicolumn{6}{|l|}{ Fertility indices } \\
\hline Services per pregnancy, ${ }^{2} \mathrm{n}$ & 1.65 & 2.04 & 2.68 & 2.01 & 0.12 \\
\hline Days open, ${ }^{2} \mathrm{~d}$ & $92.9^{\mathrm{a}}$ & $132.5^{\mathrm{b}}$ & $138.8^{\mathrm{b}}$ & $110.5^{\mathrm{ab}}$ & 0.02 \\
\hline Conception rate ${ }^{3} \%$ & 52.6 & 45.0 & 21.0 & 36.8 & 0.22 \\
\hline Repeat breeders, ${ }^{4} \%$ & 21.0 & 45.0 & 57.9 & 31.6 & 0.10 \\
\hline
\end{tabular}

${ }^{\mathrm{a}, \mathrm{b}}$ Means with different superscript letters indicate significant effect between groups $(P<0.05)$.

${ }^{1}$ The data are relative to the frequency of the problem: percentage of cows with at least 1 problem. Problems at parturition include dystocia, milk fever, and retained placenta (no metritis); problems after parturition include ketosis, lameness, and mastitis.

${ }^{2}$ Data obtained after logarithmic transformation.

${ }^{3}$ Conception rate at the first insemination.

${ }^{4}$ Cows with more than 3 inseminations per pregnancy are considered repeat breeders. 
The different degree of correlation between various proteins is not surprising, particularly when the long period is considered. The acute phase proteins present in plasma have completely different patterns of change, according to their synthesis but also to their turnover rate. In fact, haptoglobin, among the +APP measured in our trial, was the quickest to respond (increase) to inflammation, but the usual level of this protein was also rapidly recovered (Petersen et al., 2004). In fact, after an endotoxin treatment (Trevisi et al., 1996b), the time to return to the pretreatment value was $3 \mathrm{~d}$ for haptoglobin and $7 \mathrm{~d}$ for ceruloplasmin. The situation for the -APP differs: their synthesis is almost immediately reduced by the liver (Powanda, 1980), but their blood levels can be more or less decreased according to their different turnover rate or to their compartment changes within blood plasma and interstitial fluids (Fleck, 1989). Furthermore, their recovery is affected by the typical rate of synthesis with respect to the total circulating amount; for example, for albumin, the daily yield represents only $5 \%$ (Kaneko, 1997). In other words, considering haptoglobin and albumins, which presented the lowest correlation, haptoglobin had a sharp and rapid response to inflammatory conditions, whereas albumin had a smoother and more prolonged change (Nicholson et al., 2000). Therefore, the changes of +APP and-APP are closely related only at the time of inflammatory event, when positive and negative effects occur contemporaneously; in our trial, only high haptoglobin levels (Figure 2) observed at 7 DIM were exactly the reverse of albumin, retinol, and cholesterol (Figure 1). According to this hypothesis, the inflammatory phenomena occurred in our cows mainly around parturition and in the LO and INLO groups. Furthermore, our results suggest that inflammation causes a reduction in the usual synthesis of the liver proteins, besides the increased synthesis of +APP (Figure 1). The different pattern of changes of +APP and -APP make arguable their contemporaneous utilization in the LAI, with differences due to the above-mentioned factors affecting mainly-APP. Because the changes of the performance are supposed to be mainly linked to -APP synthesis and plasma levels, their blood measurements are the most promising indices for our aims.

The marked plasma decrease of -APP, particularly evident in the LO and INLO groups, is not associated with liver damage because the main indices of cell necrosis (GOT/AST and GGT in our analysis) are not different during the first month of lactation. This could help explain the fast recovery of -APP in the 4 groups, and it seems to confirm our previous suggestion (Trevisi et al., 2001): the impaired liver function is not synonymous with lower liver activity and the consequence of a damaged liver, but of diverted synthesis in the liver occurring during inflammation (i.e., the liver produces more of the +APP and less of the usual proteins; Powanda, 1980; Fleck, 1989).

The temporary impaired function of the liver-but not lower activity because it produces other proteins-in the cows with higher inflammation indices is indirectly confirmed by bilirubin, which is significantly greater in the INLO and LO groups $7 \mathrm{~d}$ after parturition (Figure 2 ). The greater value of bilirubin is, in fact, a consequence of the reduction of bilirubin clearance, which is a usual metabolic function of the liver (Tennant, 1997). A similar meaning can be attributed to the negative relationship between haptoglobin and paraoxonase (an enzyme synthesized almost exclusively by the liver) recently investigated in early lactating cows (Bionaz et al., 2007). These findings also agree with those of several authors (e.g., Katoh, 2002; Bertoni et al., 2006) demonstrating that proinflammatory cytokines cause an increased risk of liver lipidosis in puerperal cows, which may be linked to the reduced synthesis of apolipoproteins in this critical stage.

\section{Inflammatory Conditions and Cow Health}

The very high frequency of inflammatory conditions in the LO and INLO groups can be only partly explained by the serious clinical problems affecting these cows (Table 3). In fact, significantly more frequent were dystocia, retained placenta, and milk fever, all occurring close to parturition, but $<50 \%$ of these cows had clinical symptoms of disease. This confirms the suggestion of Cappa et al. (1989) that parturition or early lactation per se could be responsible for some inflammations. A possible explanation of these phenomena can be seen in the cytokine release that can be caused by trauma (e.g., during delivery), by intestine (or rumen) disorders, by some stresses that are often not easy to diagnose (Grimble, 1990). Furthermore, at least in the case of parturition in women, a release of proinflammatory cytokines has been attributed to the placenta (Hauguelde Mouzon and Guerre-Millo, 2005).

\section{Inflammatory Conditions, Milk Yield, and Energy Balance}

Milk yield in the UP group was significantly greater $(P<0.05$ vs. LO; Table 2$)$, but only in the first month of lactation. The overall milk production in the first 3 mo of lactation was not different between groups. This suggests that almost all cows were able to recover; in fact, the peak in milk yield of the INLO group was 40.3 \pm 8.0 vs. $41.4 \pm 8.3 \mathrm{~kg} / \mathrm{d}$ for UP, and only the LO group had a clearly lower milk yield $(37.3 \pm 8.8 \mathrm{~kg} / \mathrm{d}$ at peak). However, particularly in the first month of lactation 
when the effects of the inflammation were more evident, a good relationship between the severity of inflammatory phenomena and milk loss can be observed (Table 2 ). This suggests that inflammatory phenomena have direct negative effects on cow performance as expected (Elsasser et al., 2000).

Interestingly, the lower yielding cows; namely, cows in the INLO and LO groups, had greater BHBA at $7 \mathrm{~d}$ after calving $(P<0.01$ and $P=0.14$, respectively, vs. UP). This suggests that INLO and LO had a slightly larger energy deficiency despite their lower milk yield. A possible explanation could be a transient lower DMI, perhaps caused by release of cytokines (Johnson and Finck, 2001). The lower levels of blood urea, observed in INLO and LO immediately after calving, seem to confirm the lower DMI in those groups. In fact, urea is known to be related to total protein intake (Roseler et al., 1993). In our case, we have to consider that the grouping criteria allowed a similar repartition of cows in each farm; therefore, there was no difference in diet between groups, and the change in urea would mean a corresponding change of protein intake and therefore of DMI. Furthermore, it seems unlikely that lower ureagenesis occurring in cows with high liver triglyceride concentration (Zhu et al., 2000) could fully explain our results, because they are concerning the first $28 \mathrm{~d}$ of lactation and not the first $2 \mathrm{~d}$ only (Zhu et al., 2000).

\section{Inflammatory Conditions and Fertility}

In the past, a negative relationship between health status and fertility has been demonstrated by the results of Barker et al. (1998) in cows affected by mastitis, of Collick et al. (1989) in cows suffering from lameness, and of Lucy (2001) for any kind of disorder. Similarly, our results demonstrated that the cows of the groups subjected to more or less severe inflammatory conditions after calving, namely INUP, INLO, and LO, had lower fertility with respect to UP, although not always significantly so (Table 3 ). Nevertheless, of the 38 cows in groups LO and INLO, only 17 had clinical problems, whereas reduced fertility was also observed in cows without visible diseases. In fact, the proportion of cows becoming pregnant at the first insemination was $28.6 \%$ for cows with clinical problems and $29.4 \%$ for cows without clinical problems.

The results obtained with our cows, grouped according to inflammation indices and not according to clinical problems, suggest that the systemic effects of diseases mediated by proinflammatory cytokines could be a common mechanism for reproductive impairment occurring after diseases or health disorders. This hypothesis agrees with the strong improvement of fertility observed when the cows were treated with antiinflammatory drugs (acetylsalicylate) in the first few days of lactation (Bertoni et al., 2004). Moreover, it tends to confirm previous suggestions: for good fertility, a "disease-free transition" is required (Roche et al., 2000; Lucy, 2001).

It seems highly probable that, within the same herd, one of the factors of fertility impairment is inflammation during the periparturient period, but not only associated with clinical events. Among the many possible mechanisms suggested by our results, two seem the most likely, and both are connected to the effects of cytokines. The first is liver synthesis deviation (Fleck, 1989). The consequence would be a reduction of albumin, RBP (retinol), lipoproteins (total cholesterol), and many other usual proteins (e.g., the proteins involved in bilirubin clearance or the paraoxonase involved in the antioxidant activity). Some could contribute to a more severe lipidosis status (Bertoni et al., 2000; Ametaj et al., 2005), particularly in high-yielding cows, or to more negative effects of the oxidative stress. Altogether, they can reduce reproductive functionality. The second mechanism could be a worsening of the negative energy balance (Lucy, 2001), because the proinflammatory cytokines reduce feed intake (Johnson and Finck, 2001) and increase energy expenditures (Elsasser et al., 2000). Recently, we have reported a similar DMI, but lower energy efficiency (10 to $15 \%$ less) in cows with impaired liver function (Trevisi et al., 2007).

Unfortunately, we do not have data to confirm any possible mechanism; however, we can observe that the suggested negative relationship between milk yield and fertility (Butler, 2000) does not always occur. In fact, the group with higher LAI (UP) had greater milk yield and very satisfactory (or good) fertility; however, the lowest reproduction performance was observed in the INLO group, which maintained an acceptably good milk yield but had the largest negative energy balance, indicated by the numerically greater BCS losses (0.79 vs. 0.67 points of UP) and the numerically greatest NEFA and BHBA values at 7 DIM. Urea level was also lower in INLO, suggesting a slower increase of DMI.

These data confirm our previous results (Bertoni et al., 1999, 2000); namely, that high milk yield reduces fertility, but particularly when associated with periparturient inflammatory conditions. Therefore, these data also seem to confirm that a close relationship between milk yield and fertility is not obvious, as the literature emphasizes. In fact, a similar reduction of conception rate has been observed in the last $30 \mathrm{yr}$ in the United Kingdom (Royal et al., 2000), as well as in the United States (Butler, 2000), but average milk yield at the end of the considered period was completely different: $6 \mathrm{t} /$ lactation in the United Kingdom and 9 t/lactation in the United States. 


\section{CONCLUSIONS}

The results of our study have confirmed the frequent association of the periparturient period with some inflammatory phenomena; inflammations that are not always associated with clinical disease, but that often can be discovered only by specific blood indices. The same data have confirmed that inflammations are the cause of impairment in liver function (not activity, which is, perhaps, higher), and perhaps of performance (milk yield and fertility). The data appear, in fact, to be the best explanation of the strong negative relationship observed between inflammation, detected by plasma increase of +APP, and the synthesis of the usual proteins (-APP), which are reduced in plasma. Otherwise, the contemporary reduction of milk yield and fertility could be explained by impairment of metabolic liver function. However, another related explanation could be the anorexic effect of the cytokines (triggers by inflammation), because the groups more affected by inflammatory phenomena had lost more BCS and had more blood ketone bodies, despite a lower milk yield.

To conclude, our results suggest that great importance should be placed, particularly for high-yielding cows, on the reduction of causes of inflammation around parturition, not only infectious and noninfectious diseases, but also trauma, injuries, digestive troubles, and hard stress conditions. Finally, it could be helpful to evaluate (e.g., via blood indices) the inflammatory status of the cows in the first weeks after calving for a more conscious management of affected cows aimed to minimize the effects of inflammatory phenomena, particularly on reproductive performance.

\section{ACKNOWLEDGMENTS}

This research was supported by RAIZ, Research Project of the Italian Ministry of Agriculture, RZ-306.

\section{REFERENCES}

Ametaj, B. N., B. J. Bradford, G. Bobe, R. A. Nafikov, Y. Lu, J. W. Young, and D. C. Beitz. 2005. Strong relationship between mediators of the acute phase response and fatty liver in dairy cows. Can. J. Anim. Sci. 85:165-175.

Barker, A. R., F. N. Schrick, M. J. Lewis, H. H. Dowlen, and S. P. Oliver. 1998. Influence of clinical mastitis during early lactation on reproductive performance of Jersey cows. J. Dairy Sci. 81:1285-1290.

Barton, B. A., H. A. Rosario, G. W. Anderson, B. P. Grindle, and D. J. Carroll. 1996. Effects of dietary crude protein, breed, parity, and health status on the fertility of dairy cows. J. Dairy Sci. 79:2225-2236.

Beaudeau, F., H. Seegers, V. Ducrocq, C. Fourichon, and N. Bareille. 2000. Effect of health disorders on culling in dairy cows: A review and a critical discussion. Ann. Zootech. 49:293-311.

Bertoni, G., L. Calamari, and E. Trevisi. 2000. Alterazioni della funzionalità epatica nel puerperio e conseguenze sulla fertilità della bovina. Pages 195-223 in La Riproduzione in Zootecnica. Vol. III. G. Enne, and R. Rossi, ed. Ministero Politiche Agricole Forestali, Milan, Italy.

Bertoni, G., R. Lombardelli, and F. Orioli. 1999. Postpartum reproductive and metabolic behaviour of fertile and infertile dairy cows with different genetic merit. Pages 413-415 in Proc. XIII Congress ASPA, Piacenza, Italy. FrancoAngeli, Milan, Italy.

Bertoni, G., E. Trevisi, L. Calamari, and M. Bionaz. 2006. The inflammation could have a role in the liver lipidosis occurence in dairy cows. Pages 157-158 in Production Diseases in Farm Animals. 12th International Conference. N. Joshi and T. H. Herdt, ed. Wageningen Academic Publ., Wageningen, the Netherlands.

Bertoni, G., E. Trevisi, and F. Piccioli Cappelli. 2004. Effects of acetyl-salicylate used in post parturition of dairy cows. Vet. Res. Commun. 28:217-219.

Bionaz, M., E. Trevisi, L. Calamari, F. Librandi, A. Ferrari, and G. Bertoni. 2007. Plasma paraoxonase, health, inflammatory conditions and liver function in transition dairy cows. J. Dairy Sci. 90:1740-1750.

Braden, T. D., C. Fry, and J. L. Sartin. 1998. Effects of interleukins on secretion on luteinizing hormone from ovine pituitary cells. Am. J. Vet. Res. 59:1488-1493.

Bruss, M. L. 1997. Lipids and ketones. Pages 83-115 in Clinical Biochemistry of Domestic Animals. 5th ed. J. J. Kaneko, J. W. Harvey, M. L. Bruss, ed. Academic Press, London, UK.

Butler, W. R. 2000. Nutritional interactions with reproductive performance in dairy cattle. Anim. Reprod. Sci. 60-61:449457.

Calamari, L., M. G. Maianti, and G. Bertoni. 1997. Relazioni fra potenzialità produttiva, problemi nel puerperio e fertilità nella vacca da latte. Pages 99-103 in Studio Della Efficienza Riproduttiva degli Animali di Interesse Zootecnico-9 ${ }^{\circ}$ Meeting Naz., Bergamo, Italy. A. Galli and C. Previtali, ed. Coop. Paolo VI, Gorgonzola, Milan, Italy.

Cappa, V., E. Trevisi, and G. Bertoni. 1989. Variazioni ematiche e produttive nel $1^{\circ}$ mese di lattazione in bovine di allevamenti con o senza problemi "post-partum". Zoot. Nutr. Anim. 15:645-660.

Collick, D. W., W. R. Ward, and H. Dobson. 1989. Associations between types of lameness and fertility. Vet. Rec. 125:103-106.

Drackley, J. K., H. M. Dann, G. N. Douglas, N. A. Janovick Gurtezky, N. B. Litherland, J. P. Underwood, and J. J. Loor. 2005. Physiological and pathological adaptations in dairy cows that may increase susceptibility to periparturient diseases and disorders. Ital. J. Anim. Sci. 4:323-344.

Elsasser, T. H., K. C. Klasing, N. Filipov, and F. Thompson. 2000. The metabolic consequences of stress: Targets for stress and priorities of nutrient use. Pages 77-110 in The biology of animal stress. Basic principles and implications for animal warfare. G. P. Moberg and J. A. Mench, ed. CABI Publishing, New York, NY.

Fleck, A. 1989. Clinical and nutritional aspects of changes in acute phase proteins during inflammation. Proc. Nutr. Soc. 48:347354.

Fredriksson, G., H. Kindahl, and L. E. Edqvist. 1985. Endotoxininduced prostaglandin release and corpus luteum function in goats. Anim. Reprod. Sci. 8:109-121.

Grimble, R. F. 1990. Nutrition and cytokine action. Nutr. Res. Rev. 3:193-210.

Hauguel-de Mouzon, S., and M. Guerre-Millo. 2005. The placenta cytokine network and inflammatory signals. Placenta 27:794798.

Johnson, R. W., and B. N. Finck, 2001. Tumor necrosis factor a and leptin: Two players in an animal's metabolic and immunologic responses to infection. J. Anim. Sci. 79(E Suppl.):E118-E127.

Kahan, J. 1971. The fluorescence properties of vitamin A. Pages 574 586 in Vitamins and Coenzymes. Part C. Methods in Enzymology. Vol. 18. D. B. McCormick and D. L. Wright, ed. Academic Press, New York, NY.

Kaneko, J. J. 1997. Serum proteins and the dysproteinemias. Pages 117-138 in Clinical Biochemistry of Domestic Animals. 5th ed. J. J. Kaneko, J. W. Harvey, and M. L. Bruss, ed. Academic Press, London, UK. 
Katoh, N. 2002. Relevance of apolipoproteins in the development of fatty liver and fatty liver-related peripartum diseases in dairy cows. J. Vet. Med. Sci. 64:293-307.

Lucy, M. C. 2001. Reproductive loss in high-producing dairy cattle: Where will it end? J. Dairy Sci. 84:1277-1293.

Markusfeld, O., N. Galon, and E. Ezra. 1997. Body condition score, health, yield and fertility in dairy cows. Vet. Rec. 141:67-72.

Martillotti, F., M. Antongiovanni, L. Rizzi, E. Santi, and G. Bittante. 1987. Metodi di analisi per la valutazione degli alimenti d'impiego zootecnico. Quaderni Metodologici N. 8. Consiglio Nazionale delle Ricerche (CNR), IPRA, Padova, Italy.

Nicholson, J. P., M. R. Wolmarans, and G. R. Park. 2000. The role of albumin in critical illness. Br. J. Anaesth. 85:599-610.

NRC. 2001. Nutrient Requirements of Dairy Cattle. 7th rev. ed. Natl. Acad. Sci., Washington, DC.

Petersen, H. H., J. P. Nielsen, and P. M. H. Heegaard. 2004. Application of acute phase protein measurements in veterinary clinic chemistry. Vet. Res. 35:163-187.

Powanda, M. C. 1980. Host metabolic alterations during inflammatory stress as related to nutritional status. Am. J. Vet. Res. 41:19051911.

Pryce, J. E., M. P. Coffey, and G. Simm. 2001. The relationship between body condition score and reproductive performance. J. Dairy Sci. 84:1508-1515.

Roche, J. F., D. Mackey, and M. D. Diskin. 2000. Reproductive management of postpartum cows. Anim. Reprod. Sci. 6061:703-712.

Roseler, D. K., J. D. Ferguson, C. J. Sniffen, and J. Herrema. 1993. Dietary protein degradability effects on plasma and milk urea nitrogen and milk nonprotein nitrogen in Holstein cows. J. Dairy Sci. 76:525-534.

Royal, M, G. E. Mann, and A. P. Flint. 2000. Strategies for reversing the trend towards subfertility in dairy cattle. Vet. J. 160:5360.

Schrick, F. N., M. E. Hockett, A. M. Saxton, M. J. Lewis, H. H. Dowlen, and S. P. Oliver. 2001. Influence of subclinical mastitis during early lactation on reproductive parameters. J. Dairy Sci. 84:1407-1412.
Tennant, B. C. 1997. Hepatic function. Pages 327-352 in Clinical Biochemistry of Domestic Animals. J. J. Kaneko, J. W. Harvey, and M. L. Bruss, ed. Academic Press, San Diego, CA.

Trevisi, E., A. Gubbiotti, and G. Bertoni. 2007. Effects of inflammation in peripartum dairy cows on milk yield, energy balance and efficiency. Pages 395-396 in Energy and Protein Metabolism and Nutrition. EAAP Publication no. 124. Wageningen Acad. Publ., Wageningen, the Netherlands.

Trevisi, E., L. Calamari, and G. Bertoni. 2001. Definition of liver activity index in the dairy cow and its relationship with the reproductive performance. Pages 118-119 in Proc. X Int. Symp. Vet. Lab. Diagnost., Salsomaggiore-Parma, Italy.

Trevisi, E., X. T. Han, F. Piccioli-Cappelli, and G. Bertoni. 2002 Intake reduction before parturition affects milk yield and metabolism in dairy cows. Page 54 in Proc. 53rd Annu. Mtg. EAAP, Cairo, Egypt. Y. van der Honing, ed. Wageningen Acad. Publ., Wageningen, the Netherlands.

Trevisi, E., R. Lombardelli, L. Calamari, and G. Bertoni. 1996a. Variazioni ematiche del progesterone in bovine trattate con endotossine in fasi riproduttive e con modalità diverse. Pages 47-51 in Studio della Efficienza Riproduttiva degli Animali di Interesse Zootecnico, 8th Meeting Naz., Bergamo, Italy. A. Galli and C. Previtali, ed. Coop. Paolo VI, Gorgonzola, Milan, Italy.

Trevisi, E., F. Piccioli Cappelli, G. Folli, and G. Bertoni. 1996b Effects of repeated treatments with "slow release" endotoxin on dairy cows metabolism. Page 33 in Proc. 8th Int. Symp. Vet. Lab. Diagnost., Jerusalem, Israel. World Assoc. Vet. Lab. Diagnost., Jerusalem, Israel.

Wolf, G. 1984. Multiple functions of vitamin A. Physiol. Rev. 64:873-937.

Zhu, L. H., L. E. Armentano, D. R. Bremmer, R. R. Grummer, and S. J. Bertics. 2000. Plasma concentration of urea, ammonia, glutamine around calving, and the relation of hepatic triglyceride, to plasma ammonia removal and blood acid-base balance. J. Dairy Sci. 83:734-740. 